\title{
What is literature? - A systems definition
}

PIOTR SADOWSKI

One of the main methodological problems in any academic inquiry is that of definition. Defining things, processes, and phenomena is unavoidable because one has to identify and describe, however generally, the object of inquiry in order for this inquiry to take place at all. But in doing so, we immediately run into a paradox: we want to study a selected system of empirical reality because we know nothing or little about it, but in order to investigate this system, we must first define it by identifying both the elements involved and their mutual relations, as distinct from those of other systems of reality. And to define a system under investigation is tantamount to saying what this system is, whereas this is precisely the question we want to answer as a result of the inquiry, not at its beginning. In other words, by defining we assume something that is yet to be demonstrated. For example, in the present article I want to undertake a formal definition of literature, and this needs to be done at the beginning of the argument so that it immediately becomes clear what the rest of the article is dealing with. But how are we to know from the start what we are talking about if we are yet to find out what it is?

Let us analyze the logical status of the question raised in the title of this article: what is literature? To answer this question, one obviously has to understand it first; that is, one must know the meanings of all the terms used in the question. Among other things, the question includes the term 'literature', and surely the author of the question had in mind some meaning of this word, because otherwise the question would not make any sense. To use an imaginary example: in the question 'what is caraculiambro?' we must first know the meaning of the word 'caraculiambro' in order to understand the question and try to answer it, but once we know the meaning of 'caraculiambro' there is no point in raising the question at all because it is already answered. Similarly, by defining the word 'literature', the inquirer is automatically answering the initial question 'what is literature?', which in this case need not have been asked in the first place. In other words, an answer to the question 'what is literature?' is another 
question 'what is literature?', and this circular reasoning does not seem to lead us anywhere. One wonders if the 'what is x' kinds of questions are logically justified at all, despite the fact that these are exactly the kinds of questions frequently asked in academic inquiry, including literary theory.

In the case of literature, one could argue that a critic inquiring 'what is literature?' already knows something about the object in question, and only wants to find out more about it. Intellectual tradition, habit of thought, and common sense usually help us establish fairly reasonably what literature is and what it isn't, but an academic inquiry cannot be based on common sense and things habitually taken for granted. No wonder then that the need for a more formal definition of literature has perplexed literary critics and theoreticians on numerous occasions, and any introduction to or an anthology of texts in literary theory cannot afford to pass over this basic question.

For example, Terry Eagleton, in the opening chapter of his Literary Theory: An Introduction (1983: 1-16), tackles precisely this problem, and having reviewed a number of available answers to the question 'what is literature?' he ends with a negative conclusion that no such single definition exists, at least not a fully satisfactory one. Accordingly, literature has at times been defined as an imaginative, creative, fictitious, or artistic type of writing, but these characteristics - argues Eagleton - fail to distinguish between literary and non-literary texts with sufficient precision. For Russian Formalists, and later for structuralists, literature was a particular organization of language, with its own laws, structures, devices, and narrative techniques different from other forms of language use. The aesthetically minded critics in turn referred to literature as a 'non-pragmatic' type of discourse, serving no immediate practical purpose, or as 'fine writing' (belles lettres), generally regarded as 'superior' to other types of writing. Post-structuralists then spoke of literature as a 'self-referential' form of language, one that talks only about itself and has no relation to extralinguistic reality, while Marxists like Terry Eagleton regard literature as dependent primarily on value-judgments determined by social ideologies and existing powers structures. In another attempt to address the question of 'what is literature?' René Wellek (1978) painstakingly reviewed historical definitions of the word 'literature', as if the problem was mainly a philological one: to argue how the semantics of the word has changed over the centuries, rather than try to identify and describe a part of empirical reality conventionally denoted by the word 'literature'.

One could extend further the list of definitions to illustrate more specific angles or aspects of the literary process that happen to interest particular critics. Illuminating as these definitions can be in their own right, they all nonetheless reflect first of all their authors' views: philosophic, aesthetic, 
moral, political, and so on. Rather than identifying a functional aspect of reality corresponding with the term 'literature', the critics thus engage in individual assessments and judgments as to what they regard as important in literature according to their own experience, values, and opinions brought into the study of literature.

How to break the logical vicious circle as regards the very form of definition, and how to agree on a comprehensive rather than a fragmentary definition, one that would clearly distinguish the object of inquiry from the rest of empirical reality? One of the ways out of this logical impasse would be to introduce a terminological convention rather than a definition, based on certain premises agreed upon at the beginning of the inquiry. The word 'definition' has a certain 'definite', that is, final ring about it, whereas a 'terminological convention' is just that: more tentative and subject to debate, and all it does is refer to an element of reality consistent with the assumed theoretical model. When one starts from a general model rather than from the object itself, the traditional question-begging question "what is literature?' can be transformed into a more tentative inquiry: what is a useful and logical definition of literature in the light of the proposed theoretical model? And a satisfactory answer to this question should both be consistent with the model and verifiable by the available empirical data.

Following the above reservation, one should probably avoid defining literature the way it is normally done, by imposing one's preconceptions and personal views on available textual evidence, and thus largely predetermining the outcome of the inquiry. The pitfall of subjectivity and circularity of argument is difficult to avoid, however, because in order to theorize about literature, one has to be already interested in it, which means that one's prior knowledge will inadvertantly affect the theoretical considerations. To eliminate this interference, one can begin the inquiry by addressing the whole of reality with a hope that general statements will also apply to a fragment of that reality, here: literature. But such a procedure is, needless to say, impractical and useless, first of all because we are not interested in the whole of reality but only in its chosen element, and secondly because general statements that apply to all reality have no discriminating value with regard to its individual elements. If we can neither begin with the whole of reality nor with its specific element, we can follow a middle course by imposing certain limitations on the general model while retaining a degree of generalness offered by the model.

The theoretical model used in the present paper is one offered by systems theory (Mazur 1966, 1970, 1976; von Bertalanffy 1973; Laszlo 1983; and others) as a general scientific paradigm based on the laws of physics, mathematics, and logic, in themselves unaffected by any philosophical value judgments. As a formal and deductive method, systems theory starts 
with the following premises:

1 - The world exists and is intelligibly ordered, that is, open to rational inquiry; 2 - The ordering of the world implies the presence of systems understood as sets of interrelated elements organized in wholes and hicrarchies;

3 - The systems comprising the world have three co-present aspects or modes: material, energic, and informational. Information basically has to do with the nature of relations binding the elements of the systems together, in other words, with the systems' structure;

4 -- Systems interact with one another exchanging material, energy, and information. Interaction between systems is called control, the process related to the use of signs as described by semiotics, and described by physical laws and mathematical rules; 5 - Some systems have the ability to maintain inner functional equilibrium (homeostasis) with regard to energy and information, and to counteract the possible loss of that ability. Such systems will be called self-regulating or autonomous. (Mazur 1966)

In order to deduce a definition of literature from such general premises, we have to impose certain limitations on the model. We can do this by stating that what we are interested in in the present inquiry should possess the following properties:

- it should be described in terms of systems and their interactions as formulated by systems theory;

- it should have to do with control and exchange of information (signfunction);

- it should be part of culture understood as a system of conscious collective human activity;

— it should be relevant to human homeostatic self-regulation;

- it should have to do with human verbal language.

In view of the above restrictions imposed on the general systems model, I propose the following terminological convention: a system of socially organized self-regulation by means of metalinguistic artefacts will be called literature.

To understand a definition, one needs to understand all the words and terms used in it in the meanings stipulated by the adopted model. Accordingly, all the relevant terms used in the above definition of literature refer to the following elements of systems theory:

1. By 'system' is understood a set of interrelated elements (Weinberg 1975: 9; Mazur 1976: 44; Laszlo 1983: 4-5) subject to physical laws, in the sense that a system exists in three simultaneous modes: material, energic, and informational. Consequently, on the 'material' side we are dealing first of all with people involved in the literary process, either as producers or recipients, as well as with literary works as texts in the form of 
manuscripts, printed books, computer databases and so on. The 'energy' in turn determines the amount of power needed to produce literary works, including the correlative power of the authors to create their works and that of the recipients to read and understand them, as well as the sociological power needed to produce, print, and disseminate literary works in the society. Finally, 'information' determines both the structure of literature considered as a whole (its different forms and genres) and the structure and meaning of individual works. By 'structure' in turn, I understand the number and character of elements and internal relations involved in a literary work. Treating literature as a system also implies that its elements do not exist in isolation but are related to one another and to the environment (Sadowski 1992: 78-91);

2. By literature as a 'socially organized' system, I mean its collective character, in the sense that literature cannot be produced and received by only one person but must belong to a larger socio-cultural system, more precisely to the sphere of the collective psyche. For example, a poem written and subsequently hidden or destroyed can play a role in the psychic self-regulation of its author, but it does not belong to culture treated as a social system. Texts such as these lie beyond the system of socio-cultural interactions and do not normally become objects of critical inquiry. I am not saying that such isolated literary creations are not 'literary' - they can indeed have great merit in their own right — but I have decided not to include them in the proposed definition which treats literature as a collective endeavour. By 'socially organized', I also mean that there exist socio-cultural subsystems in the form of institutions responsible for the composition, storing, dissemination, and reception of literary works, such as professional societies of writers and critics, university literature departments, critical journals, publishing houses, libraries, bookshops, and so on;

3. 'Self-regulation' is to be understood as a behavior of the system leading to homeostatic restoration of its functional equilibrium, normally accomplished by means of adequate reactions to satisfy different needs. Consequently, the need will be defined as a temporary disturbance of the system's functional equilibrium due to a deficiency or excess of a particular type of information or energy (Wiercinski 1981: 35). In practice we never have to do with needs referring only to information or only to energy, but with the two modes co-existing in varying degrees. We can accordingly divide the needs into two main categories:

a. the needs involving more energy and less information will be called biological; and

b. the needs involving less energy and more information will be called cognitive. 
This division corresponds roughly to what is commonly referred to as 'bodily' or 'material' needs versus the 'spiritual' needs, respectively, but I have introduced here different terms to avoid confusion with these rather vague traditional notions. The adopted terms 'biological' and 'cognitive' do not carry any evaluative connotations and are meant to be understood strictly as stipulated in their definitions.

With regard to humans, it is possible to talk about the following types of needs, starting with the biological needs and proceeding 'upwards' in the direction of the needs involving least energy and most information:

a. the procreative need, relating to the biological replication of the organism. This is by far the most energic of needs, and its satisfaction is normally accomplished by means of instinctive, involuntary reflexes requiring almost no participation of consciousness;

b. the nutritional need, relating to the intake of energy from the environment to uphold life processes within the organism. The satisfaction of this need is likewise based to a large extent on involuntary responses;

c. the protective need, relating to the behavior aimed at avoiding situations potentially threatening to bodily integrity and homeostasis (functional equilibrium). This need will also be largely based on instinctive responses with elements of conscious exploration of the immediate environment;

d. the socio-emotional need, involving emotional contacts and interactions with other members of the group: the family, the ethnic group, and so on. This need will be satisfied both through involuntary emotional reactions towards other group members and through consciously acquired knowledge about one's social environment;

e. the exploratory need, relating to the intensified conscious penetration of the environment, both social and natural. A spectacular example of human exploratory activity is science as a socially organized endeavor aimed at collecting, storing, and utilizing information about the world acquired through abstract theorizing, active search, and experimentation ('what the world is like?'). This need has primarily to do with information, although the very process must of course be sustained by a supply of energy in the form of exploratory drive and motivation;

f. the aesthetic need, relating to the exploration and classification of the elements of the environment into patterns according to external forms, shapes, sounds, colors, and so on, and distinguished by the type of accompanying emotional response ('how the world affects me?');

g. the teleological need (from the Greek telos, goal), involving a more critical reflection and exploration of the world for sheer curiosity's sake, that is, with no direct utilitarian (adaptive) purpose. Instead, this cognitive need relates to general questions about the purpose and meaning of the 
world ('why the world is the way it is?'), and of one's individual existence. More particularly, the teleological need can be defined in terms of goals or objectives understood as imagined states concerning the individual or the society, projected mentally into the more or less distant future. The considerable involvement of consciousness and volition in the teleological need means that the desired goal can be sought even against the circumstances unfavorable to its attainment, or against the other needs (the biological ones), especially when the specific goal expressly requires that the needs of the lower order (e.g., nutritional or procreative) be suppressed. The distinguished types of needs can be related to the energy and information processes in the system as shown in Table 1.

4. Finally, the proposed definition states that literature performs its self-regulating function by means of 'metalinguistic artefacts'. By the latter, I mean physical systems coding linguistic metainformation; in other words, literary texts, oral or written. The term 'metalinguistic' refers to a symbolic or connotative use of language, defined in systems theory by different levels of control.

Control can be regarded as a cybernetic version of communication models used in semiotics to account both for the use of linguistic signs by humans, as in Saussure's and Jakobson's structural linguistics, and for the use of signs in a general sense, as in Peirce (Greenlee 1973) and Eco (1977). Marian Mazur's cybernetic model of control appears here closest to Eco's general semiotic theory (Eco 1977: 32-47), and in both models the terms 'signal', 'system', and 'code' are used in analogous senses and functions.

Table 1. Classification of needs according to information and energy involved

\begin{tabular}{|c|c|}
\hline & $\begin{array}{c}\text { Information } \\
\text { (cognitive needs) }\end{array}$ \\
\hline \multicolumn{2}{|l|}{ 7. Te lcological } \\
\hline \multicolumn{2}{|l|}{ 6. Aesthetic } \\
\hline \multicolumn{2}{|l|}{ 5. Exploratory } \\
\hline \multicolumn{2}{|c|}{ 4. Social-Emotional } \\
\hline \multicolumn{2}{|l|}{ 3. Protective } \\
\hline \multicolumn{2}{|l|}{ 2. Nutritional } \\
\hline \multicolumn{2}{|l|}{ 1. Procreative } \\
\hline & $\begin{array}{c}\text { Energy } \\
\text { (biological needs }\end{array}$ \\
\hline
\end{tabular}


Thus control has to do with interactions between systems and it describes a behavior of one system leading towards specific changes in another system (Mazur 1976: 67). Interaction involves an exchange of physical states, and so it is possible from the structural point of view to talk about differences between these states. For control to take place, a difference between physical states at the output of system $X$ has to correspond to the difference between physical states at the input of system $\mathrm{Y}$, as presented in Figure 1.

In the diagram (Fig. 1) Ix represents a transformation of signal (physical state) $x_{1}$ into $x_{2}$, and $I y$ represents a corresponding transformation of signal $\mathrm{y}_{1}$ into $\mathrm{y}_{2}$, due to the codes $\mathrm{Q}_{1}$ and $\mathrm{Q}_{2}$. Mazur defines information as the transversal transformation (difference) between signals in the control line (1970: 34-38), a definition that appears to me more precise than Eco's understanding of information as 'a statistical property of the source ... designating the amount of information that can be transmitted' (Eco 1977: 40). Systems exchange information when the difference between signals at the output of the controlling system $(\mathrm{X})$ corresponds to the difference between signals at the input of the controlled system (Y). For example, a letter written by the sender is the one read by the addressee, or a poem composed by a poet corresponds to the one read by a reader in an anthology. Information here refers to the perception of physical form: the shape of letters on a page, or the sound of words in speech, but it does not refer to an understanding of this form. In this sense, Mazur's 'information' corresponds to Eco's 'non-significant pieces of information' (Eco 1977: 41) and to the 'signifier' in Saussurian structural linguistics.

To account for the possibility of understanding of information, we have to extend the model of control by allowing the signals in both systems to be transformed into other signals. This can always happen if there is enough correlative power in the system to transform one signal into a new one, as shown in Figure 2. The new elements in the schema are further transformations of signals in systems $\mathrm{X}$ and $\mathrm{Y}$, except that while information $\mathrm{Ix}$ is coded by $\mathrm{Q}_{1}$ and $\mathrm{Q}_{2}$ into information Iy, other transformations of signals

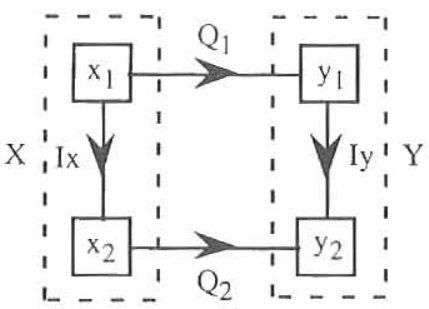

Figure 1. Information in the control line (after Mazur 1970:26) 


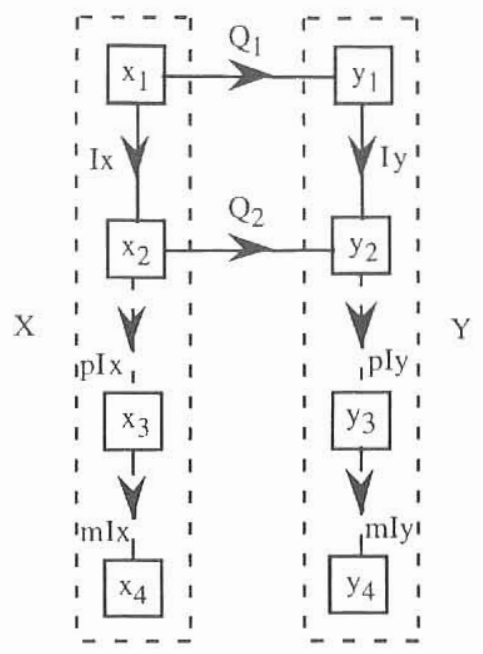

Figure 2. Information, parainformation, and metainformation in the control line

in system $\mathrm{X}$ are not coded into corresponding transformations in system $\mathrm{Y}$. In other words, the extended model of control describes associations attached to information. In particular, we can talk about two main levels of associations:

a. the first, direct level (transformation of signal $x_{2}$ into $x_{3}$ in system $X$, and transformation of signal $\mathrm{y}_{2}$ into $\mathrm{y}_{3}$ in system $\mathrm{Y}$ ) describes an association attached to information, that is, to the perception of the physical form. Transformations $\mathrm{pIx}$ and $\mathrm{pIy}$ will be called parainformation (Mazur 1970: 40), and will refer to the understanding of the literal, direct, or denotative meaning of information, corresponding to 'significant pieces of information' in Eco's communication model (Eco 1977: 41), to 'objects' in Peirce (Greenlee 1973: 48), and to the 'signified' in structural linguistics. b. the second, indirect level (transformation of signal $x_{3}$ into $x_{4}$ in system $X$, and transformation of signal $y_{3}$ into $y_{4}$ in system $Y$ ) describes an association attached to parainformation, that is, to the literal understanding of information. I will call transformations $\mathrm{mIx}$ and mIy metainformation, referring to the understanding of the nonliteral and metaphorical meaning of information, similarly to Eco's 'connotation' (1977: 54-57).

Examples of the use of information, parainformation, and metainformation in culture are legion, as any instance of communication has to involve at least one type of control. Language in particular provides ample evidence for the use of associations, involving parainformation in everyday, 
communicative use, and both para- and metainformation in such uses as allusions, hints, sarcasm, jokes, and generally poetic and literary language. In fact, it is the use of metasignals that distinguishes human language from signs and systems of communication used by animals (see also Eco 1977: 54 -57). For example, a urinating wolf is not only emptying its bladder but is also marking the boundaries of its living area, a fact that will be understood as such by other wolves: the smell alone is information (signifier), while its significance as a boundary marker is parainformation (signified). An example of an analogous level of control in the human world can be traffic signals. On the other hand, to have associations about associations (connotation, metainformation) seems to belong exclusively to the human domain and human-type consciousness.

Humor is a good case in point. A typical joke has a two-layer construction based on surface parainformation and the underlying metainformation: it is usually told in such a way that the story (information) provokes in the reader/listener specific parainformation (literal meaning), usually suspended or reversed in the final punch line, pointing to a completely new and unexpected meaning (metainformation). A well-told joke postpones this reversal of this meaning climactically until the end of the story, and a humorous effect is achieved by frustrating or confusing the recipient's expectations; that is, the recipient is usually expecting only parainformation, and what makes a joke a joke is the fact that the anticipated parainformation is at the end unexpectedly replaced by (usually opposite) metainformation. Of course, different jokes are funny to different people depending on the character of the implied metainformation. A person without specific metainformation will not understand a joke, even if he or she possesses proper parainformation to follow the surface meaning. There are intellectual jokes for educated and sophisticated people (those with proper metainformation), and there are so-called vulgar jokes that can be understood by all because the metainformation involved in them is of universal character, usually dealing with bodily functions. A joke told to a person without proper metainformation will not be understood, and the recipient may be accused of the lack of a sense of humor. A joke may also be ruined if the teller provides more information than is necessary to lead the listener to the desired meaning, or when the teller changes the order of information and suggests the right metainformation too soon, thus ruining the climax and spoiling the fun. A well-known technique used by humorists is to tell the story as if it was to be understood literally (parainformation), whereas it only makes complete sense with the implied metainformation. The joke will then be funny for a person with proper metainformation, while for a person without the metainformation, the story will be disappointing, meaningless, or confusing. 
While the presence of metainformation in jokes and other semi-literary and literary forms is a condition sine qua non of the genre, in strictly non-literary texts metainformation is normally avoided. Wherever objectivity and factuality are the key thing, control is restricted to information provoking specific and unambiguous parainformation, as in scientific texts or journalism, for example. Scientific texts are meant to provide descriptions of facts and objective, specific evaluations of these facts, not convictions, emotions, or other symbolic connotations, and must therefore be based on parainformation and not on metainformation. The same holds for journalism, which is professional when it relies only on information (faithful photography) and clear parainformation (descriptions of events), and is unprofessional when it is biased, opinionated (individual or group metainformation), or when it uses vague, figurative language. Political propaganda, like bad journalism, is based to a lesser extent on information and parainformation (facts) than on metainformation (opinions, convictions, judgments, emotions).

If factuality is not at issue, however, metainformation is used lavishly to create intentional elusive and suggestive meanings. A good instance of the type of text remaining somewhere in between the factuality of journalism and imaginativeness of literature is advertising. In fact, for advertising to be effective and appealing, it must operate both with information and with para- and metainformation. Advertisements most often use the visual code, which is easier to comprehend than the written text, because it relies basically on information requiring less correlative power to activate. The ad's information is the advertised product, usually pictured realistically, accompanied by some brief verbal description (parainformation), while metainformation is conveyed through various accompanying images stirring different associations, often unrelated to the product in any direct way. In some commercials, the accompanying associations tend to dominate almost entirely, with the advertised product occupying little space and providing no metainformation of its own. The success of visual commercials thus relies on careful balance between the realistic images of the product (information) and the attached, often unrelated images stirring multifarious para- and metainformation, whose character depends on the current interests and expectations of the public.

The involvement of metainformation places advertising halfway between simple informing (as in business and trade) and visual art, whose aim is not primarily to inform but to stimulate extended, varied, and often elusive associations in the viewers. The presence and range of metainformation can thus serve as a good gauge of artisticity, in that explicit, literal presentations (information) normally characterize the non-artistic forms, whereas implicit, suggestive presentations are typical for artistic forms. 
For example, according to this criterion (presence and extent of metainformation), scenes of explicit sex and violence in film or popular literature should be classified as less- or non-artistic, in comparison with similar scenes which only mark or suggest the acts in question. Explicit presentations or descriptions rely solely on information accompanied by limited and fairly universal and predictable associations, while implicit presentations provoke the viewers' or the readers' metainformation (imagination), which can be rich in different associations (aesthetic, intellectual, emotional), considerably enhancing the artistic experience. For people with the relevant meta-associations, explicit representations (as in pornography) are trivial, disgusting, offensive to their intelligence, and ultimately boring, while implicit, suggestive representations (as in well-painted nude figures or subtle erotic poetry) provide an intellectual, aesthetic, and emotional challenge, and are therefore more artistically effective and satisfying. Visual artefacts using only information and very limited parainformation, with little or no metainformation, are action movies, comic strips, some cartoon films, and computer games.

The proposed definition of literature postulates that the main qualitative difference between literary and non-literary use of language is the presence of metainformation and metameaning in the former. The use of metalanguage in literature rules out linguistic artefacts (texts) primarily intended to be understood literally in the precisely defined sense (parainformation), even if they, too, play a role in social or individual selfregulation. For example, journalism is generally meant to satisfy the exploratory need (curiosity about the world), but it fulfills this function primarily by means of paralinguistic artefacts (newspaper reports), and in this sense it does not belong to literature as here defined but rather to social gossip. In a similar way, philosophical or theological texts, dealing primarily with the teleological need, do not belong to literature either because they, too, operate mainly with parainformation (clear and unequivocal meaning), and if they occasionally acquire a metalinguistic character (metaphorical style), it is regarded (and rightly so) as their demerit, because clarity and precision of meaning suffer as a result. However, if a religious or a philosophical text is deliberately and extensively using a symbolic or allegorical style, it then becomes literature. For example, the Bible and some mystical, visionary texts can thus be classified as literature according to the proposed definition.

Nevertheless, not all instances of metalanguage belong to literature. Everyday verbal humor, sarcasm, allusions, and so on, based as they are on metainformation, are usually too ephemeral and volatile to form more permanent linguistic artefacts, and they do not as a result play a major role in collective self-regulation. If, however, a humorous account ceases 
to be solely an individual property by getting retold or circulated in the written form in culture, it does become literature according to the adopted definition.

Let me now sum up the possible types of linguistic artefacts considering both the nature of needs they address and their informational character, that is, whether the artefacts rely on parainformation or metainformation. Table 2 offers a classification of linguistic artefacts based on the above criteria and illustrates each type with actual examples.

The proposed definition of literature includes different types of metalinguistic artefacts referring to all needs, that is, both biological and cognitive, and comprises anything from food advertisements and pornography to subtle psychological novels, refined erotic verse, or highly symbolic poetry. One can, of course, argue that such an understanding of literature is too broad, as we are accustomed to see some difference between a commercial slogan and a line from Shakespeare. The difference, however, lies not in the type of language used, because in both cases it is predominantly metainformational, that is, metaphorical and symbolic, and one is indeed often astonished at how witty and 'poetic' verbal advertisements can be. What makes poetry, the psychological novel, moral allegory, existentialist drama, and so on different from food and health commercials is not the type of language but the character of needs that these texts cater to: the former seem to respond to the cognitive, 'higher' needs, especially the aesthetic and teleological ones, while the latter address the biological needs, especially the nutritional and protective ones.

On the other hand, it is perfectly possible to introduce a narrower definition of literature, confined only to the cognitive needs, or even only to the teleological one. In that case, literature would include only those metalinguistic artefacts that address the question of the meaningfulness and purposefulness of life. Alternatively, one can introduce a distinction whereby metalinguistic artefacts responding chiefly to the cognitive needs will be referred to as 'highbrow' literature, or literature proper (belles lettres), while metalinguistic artefacts catering for the biological needs will be classified as 'lowbrow' or 'popular' literature. A definition is only a terminological convention and is valid as long as it is useful and consistent with the general model. I have chosen a broad understanding of literature to suggest that one can talk about poetry, jokes, and commercial slogans using the same critical apparatus and terminology, although literary criticism traditionally tends to deal with the types of writing or oral composition that respond primarily to the cognitive needs, and especially to the specifically human telcological need.

One could also argue that a particular metalinguistic artefact can aim at satisfying more than one type of need at the same time. For example, 
Table 2 Classification of linguistic artefacts

\begin{tabular}{|c|c|c|}
\hline Needs & $\begin{array}{c}\text { Paralinguistic } \\
\text { artefacts }\end{array}$ & $\begin{array}{c}\text { Metalinguistic } \\
\text { artefacts }\end{array}$ \\
\hline 7. Teleological & $\begin{array}{l}\text { philosophical and } \\
\text { theological writing }\end{array}$ & $\begin{array}{l}\text { religious poetry, } \\
\text { moral allegory, } \\
\text { psychological fiction, } \\
\text { philosophical poetry }\end{array}$ \\
\hline 6. Exploratory & $\begin{array}{l}\text { scientific papers and } \\
\text { books, journalism, } \\
\text { office memos, } \\
\text { intelligence reports, } \\
\text { instruction manuals }\end{array}$ & $\begin{array}{l}\text { travel literature, } \\
\text { science fiction, } \\
\text { realistic and } \\
\text { historical fiction }\end{array}$ \\
\hline 5. Aesthetic & $\begin{array}{l}\text { philosophic } \\
\text { aestheticism, art and } \\
\text { literary criticism }\end{array}$ & $\begin{array}{l}\text { poetry, esp. on } \\
\text { nature, love and art; } \\
\text { drama, esp. opera }\end{array}$ \\
\hline 4. Social-Emotional & $\begin{array}{l}\text { lonely-hearts } \\
\text { columns, personal } \\
\text { letters }\end{array}$ & $\begin{array}{l}\text { national epic and } \\
\text { drama, folk ballads, } \\
\text { popular drama, love } \\
\text { lyrics, romance } \\
\text { literature, } \\
\text { psychological fiction }\end{array}$ \\
\hline 3. Protective & $\begin{array}{l}\text { legal tracts, acts of } \\
\text { parliament, political } \\
\text { writing, medical } \\
\text { reports, public } \\
\text { notices }\end{array}$ & $\begin{array}{l}\text { public political } \\
\text { discourse: speeches, } \\
\text { manifestoes, slogans; } \\
\text { national anthem; } \\
\text { health, clothing, } \\
\text { housing, and safety } \\
\text { advertisements }\end{array}$ \\
\hline 2. Nutritional & $\begin{array}{l}\text { cook books, recipes, } \\
\text { scientific reports on } \\
\text { nutrition }\end{array}$ & food advertisements \\
\hline 1. Procreative & $\begin{array}{l}\text { pornography, sex } \\
\text { magazines, obscene } \\
\text { graffiti }\end{array}$ & $\begin{array}{l}\text { erotic poetry and } \\
\text { fiction }\end{array}$ \\
\hline
\end{tabular}


historical fiction may be addressing the question of the meaningfulness of the life of individuals and societies of past historical periods, but it can also offer quite detailed and accurate historical knowledge, thereby addressing the exploratory need. If the writer is successful and skillful in creating atmosphere and suspense, evoking emotion, one can also talk about aesthetic qualities. Similarly, lyrical poetry can describe broodings about the meaning of existence, but it will also relate those sentiments to the socio-emotional need, or even the procreative, as in erotic poetry. John Keats's Ode on a Grecian Urn can address primarily the aesthetic need (emotional response to a Greek vase), but it is also exploratory in its imaginary reconstruction of the pictorial representations on the vase and their relation to ancient Greek culture, and teleological in its discussion of the philosophical meaning and purpose of art.

If we limit the definition of literature to metalinguistic artefacts related first of all to the cognitive needs, we will obviously have to exclude from consideration such types of texts as advertising because they do not primarily address the teleological need, despite their aesthetic appeal. No matter how witty, symbolic, and successful in creating moods the commercials can be, their primary purpose is to satisfy the 'lower', biological needs (food, clothes, health, security, physical comfort); even if sometimes they make a gesture towards the teleological need by appealing to people's sense of success and self-fulfillment. Whether the need for meaningfulness of life can be adequately satisfied through eating, physical comfort, and material prestige depends ultimately on one's individual needs and value system: for some people, it is enough; for others, it is not. As the history of religion and philosophy abundantly illustrates, the satisfaction of the specifically human need of the meaningfulness and purposefulness of life is a much more complicated problem than the modern consumer market and the advertising industry want us to believe.

To sum up: before any formal definition of literature can be furnished, it is first necessary to reformulate the very question 'what is literature?' into a more tentative inquiry that avoids circular reasoning and helps build a definition on a more solid theoretical footing. It is also necessary, strange though it may seem, not to begin with one's empirical knowledge about literature when defining the latter, because one's subjective views and preconceptions will unavoidably affect and predetermine the outcome of the debate. In the present article, I advocate an approach that does not start with available empirical knowledge about literature but with an independent general theory of systems, based on non-empirical concepts of mathematics, physics, and logic. One of the basic concepts of systems theory is that of control, analogous to the semiotic communication models and similarly able to account for the use of signs on different semantic 
levels in verbal language and in other acoustic and visual codes. addition, systems theory as a deductive method can generate spec statements referring to the behavior of living systems, includ the question of needs and homeostatic self-regulation, as well as ot. statements relevant to a particular fragment of empirical reality un investigation, here: literature.

\section{References}

Ackoff, Russel L. and Emery, Fred E. (1972). On Purposeful Systems. London: Tavistc Publications.

Eagleton, Terry (1983). Literary Theory: An Introduction. Oxford: Basil Blackwell.

Eco, Umberto (1977). A Theory of Semiotics. London: The Macmilian Press Ltd.

Greenlee, Douglas (1973). Peirce's Concept of Sign. The Haguc: Mouton.

Laszlo, Ervin (1983). Introduction to Systems Philosophy. Oxford: Pergamon Press.

Mazur, Marian (1966). Cybernetyczna teoria ukladow samodzielnych (Cybernetic Theory Autonomous Systems). Warsaw: Państwowe Wydawnictwo Naukowe.

(1970). Jakościowa teoria informacji (Qualitative Theory of Information). Warsa Wydawnictwa Naukowo-Techniczne.

- (1976). Cybernetyka i charakter (Cybernetics and Character). Warsaw: Panistwowy Instyt Wydawniczy.

Rapaport, Anatol (1986). General System Theory: Essential Concepts and Application Tunbridge Wells, Kent: Abacus Press.

Sadowski, Piotr (1992). Interpretation of literary process: A systemic approach. Studi Anglica Posnaniensia 24, 78-91.

Von Bertalanffy, Ludwig (1973). General System Theory: Foundations, Developmen Applications. Harmondsworth: Penguin.

Weinberg, Gerald M. (1975). An Introduction to General Systems Thinking. New York: Joh Wiley and Sons.

Wellek, Renc (1978). What is literature? In What Is Literature?, Paul Hernadi (ed.), 16- 2. Bloomington: Indiana University Press.

Wierciński, Andrzej (1981). Antropogeneza: ewolucja cywilizacji (Anthropogenesis: Evolution of Civilization). Warsaw: University Press.

Piotr Sadowski (b. 1957) is a Lecturer in English at the American College Dublin in Dublin. lreland〈psdowski@tcd.ie〉. His principal research interests are medieval literature, Shakespeare, systems theory, and depth psychology. His major publications include 'The greenness of the Green Knight: A study of medieval colour symbolism' (1991), 'Interpretation of literary process: A systematic approach' (1992), 'The "dog's day" in Hamlet: A forgotten aspect of the revenge theme' (1993), and The Knight on His Quest: Symbolic Patterns of Transition in Sir Gawain and the Green Knight (1996). 